\title{
REFLECTION: BENEFITS OF GAMIFICATION IN ONLINE HIGHER EDUCATION
}

\author{
Daniel A. Kaufmann, Grand Canyon University
}

\section{INTRODUCTION}

In online higher education, students are expected to overcome obstacles not typically experienced by their face-to-face counterparts (Gillett-Swan, 2017). These can include isolation, lacking of a physical learning environment (Kortemeyer, 2016), additional work or family commitments, time management concerns, being off campus, and the assumption that the student is a reliable and independent learner (Karen, 2004). In fact, a student must complete tasks in a timely manner with high efficiency and master related materials in order to excel in higher education. While different styles of student motivation exist, many students will engage in a "ramping-up" process prior to course deadlines (Urban, 2016), which means that the majority of the work is done closer to the deadline for the required task. What happens to students who reach a level of education in which there is no externally assigned deadline, such as writing a dissertations?
\end{abstract}

ABSTRACT

This article presents a reflective account of how gamification can help students overcome complex academic challenges, such as those involved in the dissertation process and other elements of higher learning. Gamification has been shown across multiple levels of academic instruction to have a positive impact on task completion by augmenting the experiential elements encountered by students who are engaging in the learning process. When a task becomes mundane, it typically lacks a positive feedback loop, which results in it becoming easier for a person to put off their intended task and forget to return to the activity prior to deadline. Many online learners participate in their degree programs in the midst of highly involved personal schedules, which can lead to lapses in organization and reduced performance as a student. Many applications have promise for improving the levels of fun, engagement, motivation, and task completion in various areas of daily life. Online faculty, can integrate these applications with existing online curricula to help students bridge the gap between passive stagnation in a course and active engagement with the course material to increase their grades earned and course-wide satisfaction.

Keywords: task completion, motivation, online learning, gamification

Games have been used throughout human history to assist people in overcoming high levels of discomfort. During the reign of King Atys of Lydia, an 18-month famine fell across the land at a time when sufficient food stores had not been preserved for this level of catastrophe (Herodotus, 2003). The solution for the people of Lydia was to eat every other day. This may seem like an incomprehensible feat for any people intimately connected to a threemeal-per-day eating cycle, but the Lydians were able to transcend their needs for food by spending the entire second day playing games. This allowed them to focus on the parts of their experience that were not cyclically devoted to their normal patterns of eating and to achieve a level of mindfulness that allowed the cravings to fade into the background of their present focus. Games in modern times can be used for a similar purpose as a healthy escape, if they are used in proper quantities at the appropriate time (Granic, Lobel, \& Engels, 2014).

When exploring incorporating the gaming 
mindset into an educational situation, it is also important to understand why we play games. Jane McGonigal (2011) in Reality Is Broken: Why Games Make Us Better, and How They Can Change the World, explains that we play for very specific reasons. The most basic reason is for enjoyment. By extension, if a person is choosing to play a game over another activity, or possibly a responsibility, it could be due to the person wanting to escape the pressure or monotony of the avoided task. Another reason we engage in play is to reduce stress. Some people will use the game as a way to pace themselves throughout their day, alternating between responsibility, or work, and enjoyment, or play (Cowley, Charles, Black, \& Hickey, 2008). By engaging in this play activity, the final possible reason for playing a game is often accomplished: to improve life satisfaction (Przybylski, Rigby, \& Ryan, 2010).

Rather than have all the games in life distract the student from completing an academic task, it should be possible to utilize this gaming mentality to reduce the stress and dread often experienced when beginning to work on an assignment in higher learning (Urh, Vukovic, Jereb, \& Pintar, 2015). By making progress on the academic task, the other goals of reducing stress and improving personal satisfaction would occur. In addition, the student would lower the barrier to engaging in the work of their online course and create shorter milestones that are easier to achieve while progressing towards completing the overall academic assignments they may have otherwise been avoiding.

\section{PERSONAL REFLECTION: THE BEGINNING}

In the quest to complete a terminal degree, many academic programs identify writing the dissertation as the final challenge a student must pass in order to be conferred the title of "doctor" (Glathorn \& Joyner, 2005). This challenge is designed to test the doctoral candidate in a variety of ways. This reflective writing piece highlights how gamifying the process can increase the focus a student brings into this particular challenge. It also identifies relevant psychological concepts related to learning and engaging in academic tasks, and it then poses important questions to frame academic work in a light that encourages passion for academic research and writing instead of settling for more negative alternatives.
There are two ways to measure the length of time it took me to move from completing my comprehensive exams to defending my dissertation. In May of the third year of my doctorate program, I passed my Comprehensive Exam. At this point, the goal of the entire program shifted from mastering the content involved in a Doctorate program in Counselor Education \& Supervision to completing the dissertation. I was driven to complete this as quickly as anyone ever had, and I knew that I had two more courses to take before entering "Continuous Matriculation," the phase where many doctoral candidates lose focus on their degree and move on to work in the field. I completed these courses as scheduled, and by the tenth month after comps I had assembled my dissertation committee and completed my prospectus. Everyone was on board and loved the topic, and we began talking about a six-month timeframe for me to deliver a literature review and methodology. I was poised to complete the goal, and in record time.

Except, that is not how this story goes. I changed jobs from a director position to a clinical one. Less responsibility would surely lead to more time for me to focus on writing. It did not. I knew what I wanted to write and how I wanted it to flow, but after everything I had written for my prospectus, research courses, and every other purpose I had ever faced with my topic, it just did not work. My motivation died.

Five months after my prospectus was approved, I had made minimal progress. I decided I would start everything from page one with the same topic but completely new writing. Nothing re-used-no excuses. After I wrote a few of my favorite topics, I was stuck. I stayed this way until six-months later. I could not bring myself to write, and I hated that I lacked the time and desire to work in a way that led to tangible progress. The calendar had moved all the way to January of my fourth year in the doctorate program. That is when I decided to use the concept I was researching to conquer this final challenge. I decided to gamify my dissertation.

\section{FLOW AND THE PSYCHOLOGY OF GAMES}

Long before video games became a household staple for entertainment, the field of psychology noticed a principle, which is now referred to in our literature as "flow." Psychological flow is the process of entering a state of consciousness where 


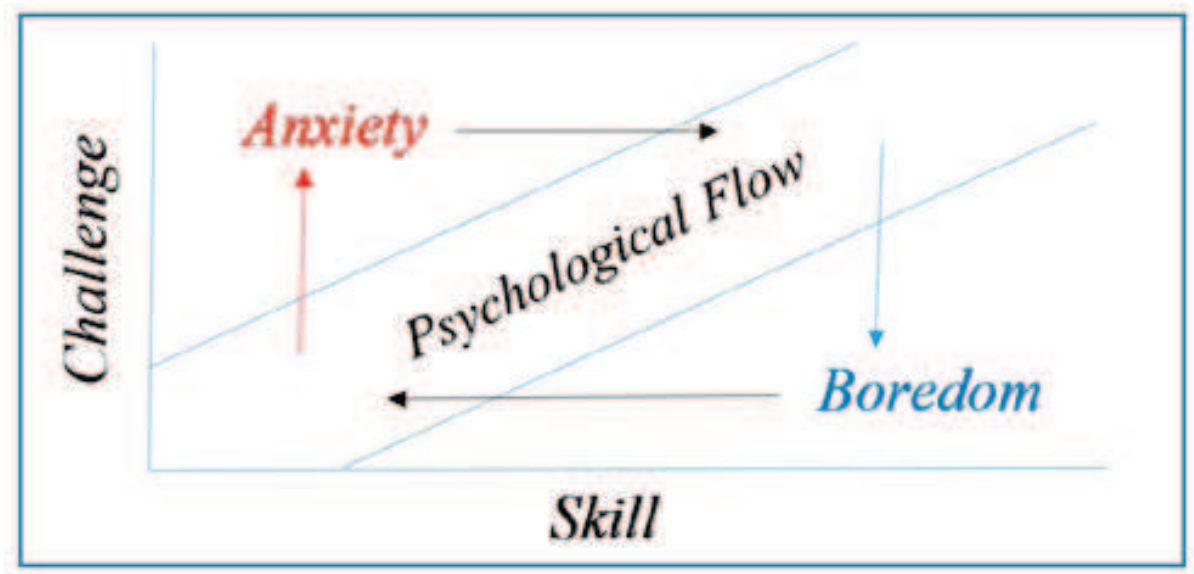

Figure 1. Psychological Flow Channel. Adapted from Csikszentmihalyi, 1975

the actions of a person become so seamless that nothing else appears to matter (Csikszentmihalyi, 2008). A person who experiences the flow state is so in tune with their activity that concentration rises beyond any relevant or irrelevant worry, and the person becomes unified with the action itself even to the point of being unaware of time. Activities that are known to initiate this form of connection with the participant include dance, playing musical instruments, chess, rock climbing, and also video games, among others.

Prior to video games being the simplest way to experience this phenomenon, Csikszentmihalyi wanted to identify the process of enjoyment at its core principles. The ability of a person to enjoy an activity eventually leads to the perception that an activity is fun. As can be seen in many problems in which counseling or remediation is necessary, the lack of enjoyment in an activity can frequently lead to avoidance of the activity in the first place, even in the face of undesired consequences involved in this decision (Ceyhan, 2011; Kuss, Crook-Rumsey, Kibowski, Wang, \& Sumich, 2018). As can be viewed in Figure I, the flow channel explains the movement of a person from boredom to anxiety, with the goal always to be increasing the challenge of a given activity through developing further skill. Once the skills are increased, the challenge will rise. If the challenge is higher than the skill, the person will work to improve their skill until a greater challenge can be attempted. In this way, the person can seize their optimal abilities in the selected life area. This is theoretically reflected in the progression of tasks in academic programs. (See Figure 1).
Universities that offer E-learning for their programs do so for many reasons. Among these is the desire to improve the motivation of prospective students to participate in furthering their education while maintaining effectiveness and efficiency across multiple life areas (Urh et al., 2015). Motivating students to engage in learning is a key to unlocking the potential for flow within any gamification mechanic. The idea is that the instructor would implement a game mechanic into their course to encourage learning through student engagement and problem solving (Martí-Parreño, Seguí-Mas, \& Seguí-Mas, 2016). However, the learner would not identify the activity as hard and unenjoyable work due to the gaming dynamic. The hope would be that the drive to excel would shift from an extrinsic motivation (get a good grade) towards an autotelic motivation (become the best I can at this task because I want to) (Csikszentmihalyi, 1975; Martí-Parreño et al., 2016). This would then move the learner from being a reactive learner who is being pushed through the material into a more proactive learner who is driven to excel by their own self (Bíró, 2014).

\section{HOW GAMIFICATION WORKS}

Jean Piaget explained that from an early age play is an integral part of a person's assimilation of new information from the surrounding environment into their developing concepts of themselves within the world (Rowley, Fook, \& Glazzard, 2018). In order for something to be considered a game, it typically will involve four elements: a goal, rules, a feedback system, and voluntary participation (McGonigal, 2011). While many people argue that all of these are involved in higher learning, the final 
component, voluntary participation, is sometimes lost amongst students at the micro level, which occurs from assignment to assignment. Therefore, while they may be participating in the degree program voluntarily, they lose the autotelic element in the short term because they would rather not be completing certain tasks. The goal of gamification is to take the principles of why a person would opt to play a game and grant some of these traits to the under-motivating tasks involved in higher education.

The process for gamification of higher learning programs was explained by Urh et al. (2015) by blending the elements of a game with what is necessary and sufficient for such learning-based programming. While online/distanced learning require that pedagogy and delivery of learning material stay acceptable, many other elements of the program can fall to the wayside without finding a way to preserve the intrinsic desire of the student to engage reciprocally with their online instructor. Many video games utilize a system where points and health bars are used to instantaneously give the player messages of success and failure. When the points go up, this is feedback that the player's action was correct for completing the task. When health diminishes, this is a sign that a mistake was made. Rewards are often visual and trackable, which give additional levels of gratification to the player when correct actions are taken. Games also successfully link small tasks over and over until a tapestry of correct actions combine to improve the skill of the player. The person can see their growth over time, as indicated by their powers or numerical markers attached to their character (or avatar). This lets them know how far they have come and allows them to plan for their next challenges based on their mastery of the game. If just a facet of these principles can be adapted into the online learning environment, the student would have an enhanced academic experience in countless areas, some of which would include motivation to continue and complete, engagement, effectiveness, efficiency, knowledge acquisition, and the experience of flow (Bíró, 2014; Martí-Parreño et al., 2016; Urh et al., 2015).

\section{PERSONAL REFLECTION: CLIMBING THE MOUNTAIN}

Now, to explain how gamifying my dissertation changed everything. I had heard about a few of these apps for gamification of life tasks through reading for my literature review. I had to make myself accountable. I decided that January that I was going to finish my doctorate in 2016. I started simple with an app called Swipes. With this app you create one list of tasks, and as you get to them in your day, you swipe right to mark that you have completed the task, which gives you a positive beep and the satisfaction of now seeing a shorter list. If you need to postpone the task, you can do so by swiping left and then touching the length of the deferment. When you have completed every item on your list, it congratulates you with a picture, a cheerful tone, and a notification of how many days in a row you have been able to accomplish this. I created my first list with only one item: Make Positive Progress.

I remember the first time I noticed that I had a streak of one week. I saw this and decided to take advantage of the social network sharing features in the app. I was so proud. I had done something that I had never accomplished at previous times when I was motivated. The app allowed me the flexibility to design my own rules (like what constitutes "Positive Progress"), but it also emphasized my choice in the way I lived my life and spent my time, which could then be used to make progress. I remember numerous times when I was making coffee so I could sit at my PC and game with my friends, the phone would beep and remind me to complete my goals for the day. Just like that, my gaming session would become a dissertation session first, until I felt good about my progress for the day. Sometimes, I would write five or more pages, seizing the feeling of flow as the ideas in my mind filled section after section, pulling my resources from Endnote and knowing exactly where to place them without a second thought. Other days I would find two new articles and read them. A few times, I would turn on my PC just to complete a paragraph or even write two sentences. The point is, something is better than nothing, and the app helped me to directly connect with this message.

I soon ran into more complex tasks, which required lists that are more intricate. At those points, I used another app to complement the improvements I had already made called Habitica (habitica.com). This app takes the premises of oldschool role-playing games (RPG) and allows you to make very specific lists, earn experience for your 
avatar character, and become more magical as you accomplish things in the real world. I used this app once deadlines became more nuanced in working with my committee, sending emails to important authors from my literature review, interacting with the IRB, advertising my study online, and so on. I kept going because I had created the large deadline, but I had also created hundreds of smaller deadlines. I could not skip a day unless it was unavoidable. I had two different streaks of 100 days or more that year using Swipes, and I made my character in Habitica a max-level mage with all the high-difficulty goals I accomplished on time. In addition, I completed my dissertation and graduated before the end of that year.

\section{INTEGRATING GAMIFICATION APPS INTO HIGHER EDUCATION}

An important consideration when utilizing a gamification app is to understand how it provides feedback and progression. For example, what kinds of lists and scoring methods are provided to the user as they move through their day-to-day experience with the app? Next, it is important to find an app that provides feedback in a way that can consistently enable the user to excel in their e-learning process. Also, if the student wants to get into a habit of completing the weekly reading by the second day of the week, can the gamifying app provide this sort of notification? Finally, once an app is identified for use, can it be structured by the course instructor, or is it up to the student to have the initiative to create all these systems on their own?

Although numerous gamification apps exist (Superbetter, Habitica, Task Hammer, Chore Wars, etc.), it is important to choose one that allows for the tasks to be suitable for the overall goal. For instance, Habitica allows the user to create smaller objectives with lower rewards and then list larger objectives, which are reserved for tasks that provide their avatar with a sizable boost to their experience meter. This app also differentiates between habits, daily tasks, and a to-do list that consists of things which must be completed only once. For students in a graduate program, this can be useful, as it allows for the student to list tasks such as reading the textbook or sending emails in a different manner, such as "Complete Week 1 Assignment." The goal of using a method such as this is to help the student connect their larger goal for being in the program (i.e., career advancement) with the smaller tasks that somehow feel disconnected from the process of earning the degree, such as reading and writing (Urh et al., 2015).

In maximizing on the RPG roots of the app, Habitica and similar apps are useful for higher education, as it allows for the formation of groups or guilds, which enables the instructor to create goals that can be pushed out by the system to all people belonging to that group. This can be important for facilitating communication between students and with the instructor throughout the course. While the traditional method for e-learning would consist of the instructor posting a weekly announcement, the gamification app would allow the instructor to send out a series of linked tasks that show the student instantly what is perceived to be the path for success to complete a given assignment. Instead of a student wondering how to structure the writing assignment, the To-Do list could already consist of a task for each section, labeled as "Write Section: . . ." This also allows for the basic questions to be instantly understood, so any question between students and faculty can bypass simple questions and move straight to more involved questions, such as those related to content or academic processes. As technology continues to develop, more advanced processes for supporting students will become available. Currently, it appears there is a substantive benefit to online, or even classroom-based, instructors to integrate gamification principles into the procedures of higher learning.

\section{DISCUSSION}

The obstacles faced by students in online learning programs can take some student's focus off the normal supports a student in a traditional campus environment would have. Such supports include interactions with peers, direct interactions with faculty, being comfortable asking questions of varying importance levels, and formulating student identity (Hurst, Cleveland-Innes, Hawranik, \& Gauvreau, 2013). The pursuit of a degree becomes more efficient when done in an online medium, sometimes at the cost of certain structures that lend themselves to the formulation of this identity. Without this identity, some students may delay work on certain required tasks, because they 


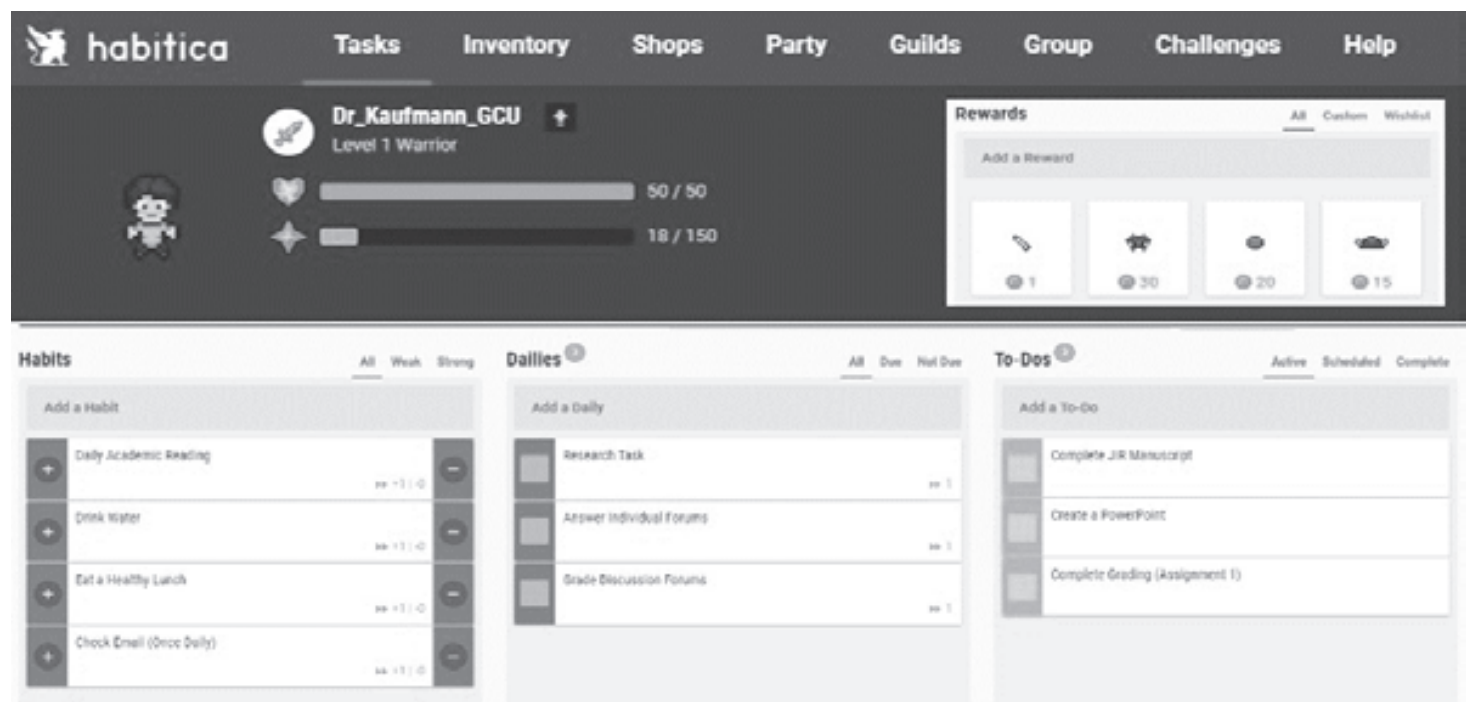

Figure 2. Sample of Habitica Dashboard Images. Image adapted from content on https://habitica. com (HabitRPG, 2018)

lack a psychological connection between what motivates them to engage in activities from other life areas (such as work, family, etc.), and what motivates them to complete their academic task. The presentation of an incentive for learning can change the outcome of this decision (Anderson, 2016), which has a profound effect on overall student engagement throughout the medium of their chosen program. Gamification of the online classroom could help to bridge this gap and lead to higher student satisfaction and success.

As with many online tools, the key to integration in the e-learning environment starts with the faculty member. If the instructor believes in the technology, they will find ways to maximize its use in the course(Martí-Parreño et al., 2016). The incentives granted by gamification apps can change the way a student feels about an activity as well. A task that otherwise would have been avoided to the point of procrastination can sometimes be engaged simply through creating a short-term reward to the player within such an app. The presentation of progression and feedback are key to games and are also critical to the education progress. Gamifying the online assignments gives an intermediary form of feedback between the student beginning the task and submitting it and also between submission and receipt of instructor grading/feedback. Academic progression comes in the form of the student engaging with increasingly challenging content and completing assignments that match these higher levels of content intensities. However, this is a slower pace than what commonly motivates a distanced e-learning student who is focused on most efficiently learning while living their hectic life. Gamification also allows the student to form an identity around their avatar in the app. They must work on the assignment so their avatar does not die. Over time, they may even develop a sense of pride in their avatar the same way they would in certain video games that are founded on character creation dynamics (Jin, 2011).

By developing this sense of pride in their tangentially formed student identity (Hurst et al., 2013) - a welcome side effect of this form of gamification - it becomes more likely that the state of psychological flow could be achieved while working on their assignments (Csikszentmihalyi, 2008), especially those involving academic writing. Flow is the state of optimal experience, when the activity is engaged to the point where it is what the person is in those moments. This intrinsic form of motivation, to become a master of the content with intentionality, can become more powerful than the external goal of getting a degree or eventually getting a better job. This is because those goals are long-term and far from the present moment when the work must be completed. Gamification helps to focus the student on the short-term goals that can be engaged in the present. These apps have the power to take the psychology of what makes video games fun by applying the principles of 
reward and feedback to the classroom. It enhances the behavioral conditioning of our minds to the point where the student will want to learn without realizing they wanted to all along.

\section{CONCLUSION}

Efforts to integrate gamification principles into online higher education courses could result in expanded mechanisms of motivation for certain kinds of students. This process highlights a connection between long-term goals and short-term drive to complete tasks, which often is lacking in self-motivated learning environments. Isolation and extenuated feedback loops between the student and the professor can be overcome by creating a process for continual reward through the student leveling up their avatar during their online coursework. While a task may seem cumbersome on its own merit, it becomes a source of gratification when the alternate deadlines of the daily task are paired with the desire to survive in the gaming overlay projected onto the learning process. The creativity of the student to survive in the gaming elements can then lead to thriving in the course gradebook, which can improve satisfaction with their course faculty and the academic program overall. As time progresses, gamification resources available to faculty of all teaching styles are expected to evolve. As this occurs, students will only be bound by what work they are willing to put forth to fulfill each type of goal on the macro and micro levels. This article was written to explain one account of using gamification to motivate the completion of advanced academic tasks and to present a literature review that explores the connection between student challenges in online learning, motivation for student action, and the use of gamification as a tool capable of integration into online learning environments. 


\section{REFERENCES}

Anderson, J. R. (2016). Student engagement and the learning incentive program: Evidence and applications. Sensoria: A Journal of Mind, Brain \& Culture, 12(1), 28-37.

Bíró, G. I. (2014). Didactics 2.0: A pedagogical analysis of gamification theory from a comparative perspective with a special view to the components of learning. ProcediaSocial and Behavioral Sciences, 141, 148-151. doi:10.1016/j. sbspr0.2014.05.027

Ceyhan, A. A. (2011). University students' problematic Internet use and communication skills according to the Internet use purposes. Educational Sciences: Theory \& Practice, 11(1), 69-77.

Cowley, B., Charles, D., Black, M., \& Hickey, R. (2008). Toward an understanding of flow in video games. Computers in Entertainment, 6(2), 20:21-20:27. doi:10.1145/1371216.1371223

Csikszentmihalyi, M. (1975). Beyond boredom and anxiety. San Francisco, CA: Jossey-Bass Publishing.

Csikszentmihalyi, M. (2008). Flow: The psychology of optimal experience. New York, NY: Harper Perennial Modern Classics.

Gillett-Swan, J. (2017). The challenges of online learning: Supporting and engaging the isolated learner. Journal of Learning Design, 10(1), 20-30. doi:10.5204/jld.v9i3.293

Glathorn, A. A., \& Joyner, R. L. (2005). Writing the winning thesis or dissertation: A step-by-step guide. Thousand Oaks, CA: Corwin Press.

Granic, I., Lobel, A., \& Engels, R. C. M. E. (2014). The benefits of playing video games. American Psychologist, 69(1), 66-78. doi:10.1037/a0034857

HabitRPG. (2018). Habitica (3) [Mobile application software]. Retrieved from https://habitica.com/

Herodotus. (2003). The histories: Reissue edition (A. De Selincourt, Trans.). In J. M. Marincola (Ed.), (p. 716). London, England: Penguin Classics.

Hurst, D., Cleveland-Innes, M., Hawranik, P., \& Gauvreau, S. (2013). Online graduate student identity and professional skills development. Canadian Journal of Higher Education, 43(3), 36-55.

Jin, S.-A. A. (2011). "My avatar behaves well and this feels right": Ideal and ought selves in video gaming. Social Behavior and Personality, 39(9), 1175-1182. doi:10.2224/ sbp.2011.39.9.1175
Karen, H. (2004). Teach them to fly: Strategies for encouraging active online learning. The Turkish Online Journal of Distance Education, 5(2), 10-14.

Kortemeyer, G. (2016). Work habits of students in traditional and online sections of an introductory physics course: A case study. Journal of Science Education and Technology, 25(5), 697-703. doi:10.1007/s10956-016-9624-6

Kuss, D. J., Crook-Rumsey, M., Kibowski, F., Wang, G. Y., \& Sumich, A. (2018). Problematic mobile phone use and smartphone addiction across generations: The roles of psychopathological symptoms and smartphone use. Journal of Technology in Behavioral Science. doi:10.1007/s41347-0170041-3

Martí-Parreño, J., Seguí-Mas, D., \& Seguí-Mas, E. (2016). Teachers' attitude towards and actual use of gamification. Procedia-Social and Behavioral Sciences, 228, 682-688. doi:10.1016/j.sbspr0.2016.07.104

McGonigal, J. (2011). Reality is broken: Why games make us better and how they can change the world. New York, NY: Penguin Group.

Przybylski, A. K., Rigby, C. S., \& Ryan, R. M. (2010). A motivational model of video game engagement. Review of General Psychology, 14(2), 154-166. doi:10.1037/a0019440

Rowley, C., Fook, J., \& Glazzard, J. (2018). Adopting a student-led pedagogic approach within higher education: The reflections of an early career academic. Reflective Practice: International and Multidisciplinary Perspectives, 19(1), 35-45. doi:10.1080/ 14623943.2017.1351352

Urban, T. (Producer). (2016). Inside the mind of a master procrastinator [Video File]. TED Talk. Retrieved from https:// www.ted.com/talks/tim_urban_inside_the_mind_of_a_ master_procrastinator

Urh, M., Vukovic, G., Jereb, E., \& Pintar, R. (2015). The model for introduction of gamification into e-learning in higher education. Procedia-Social and Behavioral Sciences, 197, 388-397. doi:10.1016/j.sbspr0.2015.07.154 


\title{
METACOGNITIVE MENTORING FRAMEWORK
}

\section{REDUCE STUDENT ATTRITION IN ONLINE EDUCATION}

\author{
Lisa Marie Portugal, American College of Education
}

\begin{abstract}
This paper summarizes a veteran instructor's experience during a short, yet intensive mentorship within a Community of Practice (CoP) framework. As a member in a Participatory Action Research mentoring lcoaching project, the educator gained new insights and knowledge about how to better serve first-year, entry-level, College 100 learners. Key insights cultivated via a peer coaching and mentoring process helped the educator develop specific instructional best practices better suited to the cognitive, constructivism online learning format designed for first-year learners. The most profound growth experiential learning take-away from the coaching and mentoring process was the understanding of and new skills applied that work best with the student population. Having veteran experience instructing advanced learners for a variety of institutions, the educator learned that instructional techniques cannot be applied uniformly when teaching in a first-year classroom compared to more advanced learners. In addition, the educator provides many of her best practices she uses in all her classrooms at many institutions she teaches for. She shares them with you in this book. Novice and veteran educators and trainers in any instructional environment will find useful teaching tools to benefit learners of all ages.

\section{INTRODUCTION}

This discussion is about the personal and professional account of a veteran, instructor who experienced a metacognitive, peer mentorship. The discussion explains the issues and challenges, the process, and the learned best practices to support $1^{\text {st }}$ year online students at a for-profit higher education institution. The goal forthereaderis to:(1) understand the value of a metacognitive, peer mentorship, and (2) learn super cool instructional techniques to support online learners in creative, inventive, engaging ways. My experiences throughout this process might help educators, coaches, mentors, human resource staff, administration, managers, trainers, and students learn new ways of interacting and producing in any educational setting. The value of this discussion might: (1) help reduce drop-out rates, (2) engage, inspire, challenge, motivate, and support learners, and (3) assist management in

professional development activities when training educators in any educational environment.

The beauty of this discussion is that anyone can find specific instructional best practices to support their interactions throughout the learning process whether one is a student, an educator, or a manager of educators and trainers. The peermentorship process and the learned best practices can be applied in any educational setting and by anyone interested in an improved learning process. Students can learn how to interact in an educational setting to improve their performance. Educators can learn how to support learners with new, differentiated instructional techniques for any age and learning style. Managers can learn how to support educators during training initiatives while providing effective, intuitive instructional techniques and take-aways.

Attrition is always a concern for all learning
\end{abstract}


environments. The instructional strategies presented can be incorporated in any educational setting and include intuitive, creative, technology components to support the learning process. The purpose of this metacognitive, peer mentorship not only enhanced student engagement and reduced attrition, but also supported faculty instructional development. I experienced the following concepts in action during the online faculty mentorship:

1. self-regulated learning process,

2. interactions with cognition and metacognition,

3. gaps in knowledge,

4. using advanced learning technologies,

5. intelligent tutoring systems,

6. information processing theory,

7. proposing future directions,

8. activities offered before, during, and after lessons or as ongoing assignments in an online course,

9. improving problem-solving skills,

10. using metacognition principles to enhance student learning,

11. increased teacher awareness of student thinking,

12. 'teachers' awareness of students' learning can be practically enhanced (Lee, Irving, Pape, \& Owens, 2015),

13. learning attitudes and engagement (Lee, et al., 2015),

14. teachers' feedback is a critical instructional strategy"(Lee, et al., 2015),

15. classroom interactions can be enhanced by "shared issues or difficulties" increasing a "positive Sense of Community" (Lee, et al., 2015),

16. exploration of multimedia instructional presentations,
17. teacher's use of language that explicitly targeted students' metacognitive knowledge altered their metacognition,

18. "metacognitive thinking strategies with different teaching strategies" (Lee, et al., 2015),

19. collaborative "online inquiry" (Lee, et al., 2015),

20. Personal Online Inquiry,

21. professional learning community (PLC), and

22. at-risk, metacognition, student retention, and student achievement,

23. professional coaching and mentoring,

24. peer coaching and mentoring,

25. Community of Practice (CoP) (Antonietti, Colombo, \& Di Nuzzo, 2015; Azevedo, Mudrick, Taub, \& Wortha, 2017; Chekwa, McFadden, Divine, \& Dorius, 2015; Efklides, 2017; Huang \& Chang, 2013; Laskey \& Hetzel, 2010; Lee, et al., 2015; Millis \& IDEA, 2016; Mytkowicz, Goss, \& Steinberg, 2014; Özcan, 2016; Prytula, 2012; Thomas \& Anderson, 2014; Zepeda, Richey, Ronevich, $\&$ Nokes-Malach, 2015).

The peer-mentoring and Participatory Action Research process changed the instructor's best instructional practices to align more appropriately with a first-year cognitive, constructivism online classroom environment. The resulting coaching and mentoring process: (1) enhanced job satisfaction, (2) reduced isolation, (3) modeled more appropriate instructional practices for facilitating in a first-year online classroom, and (4) allowed opportunity to connect with and learn from a network of faculty peers (Algozzini, et al., 2016). The Community of Practice (CoP) mentorship model helped the instructor develop a stronger sense of cognitive instructional practices to apply in her first-year classroom. The following categories interpret the most original approaches of a cognitive perspective regarding learning: (1) reciprocal teaching, (2) cognitive apprenticeship, (3) inquiry learning, (4) problem-based learning, (5) anchored instruction, and (6) discovery learning (Yilmaz, 2011). 